\title{
Use of Lubricant at Meatus and Circumcision Site in Younger Children Prevent Post Circumcision Meatal Stenosis : A Randomized Control Trial
}

\author{
Mondal $\mathrm{SK}^{1}$, Ali MA², Alam $\mathrm{MK}^{3}$, Hasina $\mathrm{K}^{4}$, Talukder $\mathrm{AR}^{5}$, Yusuf $\mathrm{MA}^{6}$, $\mathrm{Khan}_{\mathrm{JG}^{7}}$
}

\begin{abstract}
Background: Circumcision is the most common surgical procedure performed in boys through out the world. Meatal stenosis is one of its late complications. Objective: The aim of the present study is to see the effectiveness of use of lubricants vaseline-petrelium jelly) during arumcision meatal stenosis. Methodology: A randomized control trial was performed, in which two groups of boys younger than two years old underwent circumcision according to dissection (sleeve) method. The parents in the study groups were strictly instructed to use petroleum jelly on the meatus and circumcision site at every morning or after each diaper change where necessary for three months. On the other hand parents in the control group were instructed not to use any lubricants or topical medication on the same site. The boys were followed up regularly and evaluated for meatal stenosis, bleeding and infection. Results: A total of 120 boys were recruited $\&$ in each group comprised of 60 boys. None of the boys in the study group develop meatal stenosis , but $6(10 \%)$ in the control group develop meatal stenosis $(\mathrm{p}<0.05)$. Infection of the circumcision site was seen in $1(0.6 \%)$ and $3(5 \%)$ children in the lubricant and control groups, respectively $(p<0.05)$ and bleeding was seen in $3(5.0 \%)$ and $6(10.0 \%)$ respectively. Conclusion: Based on the findings of this study, it seems logical to use a lubricant jelly for prevention of post circumcision meatal stenosis and other complications. [J Shaheed Suhrawardy Med Coll, 2013;5(1):35-38]
\end{abstract}

Keywords: Circumcision, lubricants, meatitis, meatal stenosis

Received: December 2012; Revised: March 2013; Accepted: May 2013

\section{Introduction}

Circumcision means removing the foreskin that naturally covers the glans penis ${ }^{1}$. Circumcision is a surgical procedure which is widely carried out among Muslims and the Jewish ${ }^{2}$. It is used for centuries to perform on the ground of medical, religious and several other reasons. Children undergoing circumcision certainly are at a risk for complications. Neonatal circumcision in Jordan remains a frequent surgical procedure that is performed by a variety of practitioners, including urologists, family practitioners, obstetricians, general surgeons and Mohels ${ }^{2}$. Although the procedure is performed by multiple specialists, overall results are excellent. All surgeons seem circumcision is a simple operation, but still it is dangerous and carries potential risks to the patient. As a surgeon, it is needed to weigh up these risks carefully against the possible benefits of any surgical intervention ${ }^{3}$. Approximately $25 \%$ of the total world male population is circumcised and circumcision remains one of the oldest and commonest operations performed all over the world ${ }^{2}$. The complication rates of the procedure range between $0.19 \%$ and $3.1 \%{ }^{2}$. Despite this and many other similar recommendations, the procedure has continued to be performed even to a greater degree with virtually all children undergoing circumcision in the neonatal period in some communities ${ }^{4}$. Boys experience hemorrhage, infection, and ulceration; the urethral opening narrows due to scarring ${ }^{5}$. At present, approximately $70 \%$ of obstetricians, $60 \%$ of family practitioners, and $35 \%$ of pediatricians practice newborn circumcision ${ }^{6}$. The British Medical Association has recommended that circumcision should be

1. Dr. Susankar Kumar Mondal, Assistant Professor, Department of Pediatric Surgery, Bangabandhu Shik Mujib Medical University, Dhaka

2. Dr. Md. Ansar Ali, Assistant Professor, Department of Pediatric Surgery, Jessore Medical College \& Hospital, Jessore

3. Dr. Md. Kausar Alam, Associate Professor, Department of Anatomy, Pabna Medical College, Pabna

4. Dr. Kaniz Hasina, Assistant Professor, Department of Pediatric Surgery, Dhaka Medical College \& Hospital, Dhaka

5. Dr. Abdur Rabban Talukder, Senior Consultant, Department of Surgery, General Hospital, Sirajgonj

6. Dr. Md. Abdullah Yusuf, Lecturer, Department of Microbiology, Shaheed Suhrawardy Medical College, Dhaka

7. Dr. Jaglul Gaffer Khan, Medical Officer, Surgery OPD, Dhaka Medical College \& Hospital, Dhaka

Correspondence :

Dr. Md. Ansar Ali, Assistant Professor, Department of Pediatric Surgery, Jessore Medical College \& Hospital, Jessore, Bangladesh;

E-mail: dr.ansar09@gmail.com; Cell no: +8801912770441

Conflict of interest: No conflict of interest

Financial Support: None

Contributions by authors: Dr. S. K. Mondol, Dr. M. A. Ali, Dr. M. K. Alam \& Dr. K. Hasina conducted the research work \& prepared the manuscript. Dr. A. R. Talukder \& Dr. J. G. Khan have revised and have corrected the article. Dr. M. A. Yusuf has done the statistical works. 
performed only for medical reasons ${ }^{7}$. Routine neonatal circumcision has become a controversial issue in the past 2 decades as many of the previously accepted medical indications have come under considerable scrutiny ${ }^{7}$. Although many families choose to have their male infants circumcised for cultural, religious, or hygienic reasons, only a few accepted medical indications are recognized like phimosis, paraphimosis, balanitis and posthitis ${ }^{6}$. Circumcision is also recommended in male infants and toddlers who develop UTIs and children who require clean, intermittent catheterization to facilitate this procedure ${ }^{8}$. Meatitis, an inflammation generally secondary to ammoniacal diaper irritation, has been cited as the underlying cause of secondary meatal stenosis. The lack of protection by the foreskin in the circumcised male is thought to correlate with an increased incidence of meatitis. Meatal narrowing has been noted to occur more commonly in the circumcised male. The formation of a ventral lip of tissue is characteristic of secondary meatal narrowing and may cause deflection of the urinary stream upward ${ }^{9}$. Meatal stenosis is one of its late complications ${ }^{10}$. Several studies have been carried out regarding appropriate age of circumcision, early and late complications of circumcision, the effect of circumcision on reducing the urinary tract infection \& comparing the different techniques for doing circumcision $^{11,12,13}$. Nonetheless, published study lack enough suggestions on post circumcision care, such as the use of mineral oils for reducing complications.

Some authors have reported routine use of lubricants to the meatal area after circumcision ${ }^{14}$. This study was undertaken to perform a randomized control trial to evaluate postoperative lubrication of meatus and circumcision site for prevention of meatal stenosis.

\section{Methodology \\ Study population and study design}

It was a randomized control trial study which was conducted in the Department of Pediatric Surgery at Dhaka Medical College \& Hospital during the period of September 2008 to October 2009. A total 120 boys of less than two years of age were taken for the study. Patients having severe congenital anomalies like hypospadius, web penis and age above two years were excluded from this study.

\section{Randomization}

A simple random sampling technique was done that was equally divided into two groups. Named as Group A which was study group, odd number 1 st case \& every alternate case and Group B control.

\section{Intervention}

Details history and clinical examination and relevant investigations like blood for $\mathrm{Hb} \%$, bleeding time \& clotting time, X-ray chest, urine for routine examination and culture were performed. Operations were performed under general anesthesia as a day care surgery. Just before operation all patients were strictly checked to exclude preoperative meatal stenosis by using $5 \mathrm{~F}$ lubricated feeding tube below age one year and $7 \mathrm{~F}$ lubricated feeding tube below two years of age. Passing of well lubricated feeding tube through the meatus exclude pre operative meatal stenosis. All procedures were done by same surgical procedure by dissection (sleeve) method. Most of the operations were done by same surgeon. Suture materials of all patients were same (5-0 atromatic plain catgut ). After performing the procedure a povidone iodine soaked gauge piece was applied on operative site for few hours. Patients of study population were strictly instructed to apply simple petroleum jelly (Vaseline) locally at the site of circumcision site and meatus at every morning for three months. On the other site patients in the control group was instructed not to use any topical medications or petroleum jelly (Vaseline) on to the operative site.

\section{Outcome measures}

Follow up total number of follow up were eight, within three months. First was within a week for one month; then twice in a month for two months. During follow up the following points were noted like presence of small meatus with lateral traction ventral edges appears to be fused or not, abnormal strength or direction of urinary stream, discomfort with urination and incontinence, bleeding at the end of urination \& prolong emptying of bladder.

\section{Ethical issue}

The study protocal was approved by the ethical committee of Dhaka Medical College, Dhaka. informed consent from legal guardians.

\section{Statistical analysis}

All data were recorded systematically in preformed data collection sheet. Data was plotted on Microsoft Excel and analyzed with SPSS version 17. The association of qualitative variables was measured by using Chi-square test and association between quantitative data were measured by independent $\mathrm{t}$ test. 95\% confidence limits were taken. Probability value $<0.05$ were considered as level of significance. Quantitative data were expressed as mean and standard deviation and qualitative data were expressed as frequency and percentage.

\section{Results}

A total of 120 patients of age below two years who fulfilled the inclusion criteria were participated in the study. The mean age was $15.40 \pm 7.21$ months (range, 1 months to 23 months ) for the children selected in the lubricant group and

Table 1: Distribution of patients by age

\begin{tabular}{lccc}
\hline Age (Months) & Group A & Group B & p value* \\
\hline $1-12$ & $33(55.0)$ & $20(33.3)$ & \\
$12-24$ & $27(45.0)$ & $40(66.7)$ & \\
Total & $\mathbf{6 0}(\mathbf{1 0 0 . 0})$ & $\mathbf{6 0}(\mathbf{1 0 0 . 0})$ & \\
Mean \pm SD & $15.40 \pm 7.21$ & $17.35 \pm 7.01$ & 0.136 \\
\hline *Independent t test has been performed. & & \\
** Parenthesis indicates percentage. &
\end{tabular}


$17.35 \pm 7.01$ months ( range, 20 days to 23.5 months ) for those in control group $(\mathrm{p}=0.136)$ (table 1). Non-specific meatitis was seen in $1(0.7 \%)$ and $3(5.0 \%)$ children in the lubricant and control groups, respectively $(\mathrm{p}<0.05)$. Three boys $(5.0 \%)$ in the lubricant group and six boys $(10.0 \%)$ in the control group had post circumcision bleeding $(\mathrm{p}<0.05)$.

Table 2: Distribution of per operative complications by groups

\begin{tabular}{lccc}
\hline Complications & Group A & Group B & p value* \\
\hline Non-specific meatitis & $1(0.7)$ & $3(5.0)$ & 0.05 \\
Hemorrhage & $3(5.0)$ & $6(10.0)$ & 0.05 \\
Total & $\mathbf{6 0 ( 1 0 0 . 0 )}$ & $\mathbf{6 0}(\mathbf{1 0 0 . 0})$ & \\
\hline
\end{tabular}

* Chi-square test has been done corrected by Yates' correction test due at least $20 \%$ of expected frequencies are less than 5

** Parenthesis indicates percentage.

Table 3 shows the distribution of meatal stenosis by groups within three months. None of the children in the lubricant group develop meatal stenosis, while, 6(10.0\%) in the control group develop post circumcision meatal stenosis $(p<0.05)$. There is statistical significant difference in post operative complication between the groups $(\mathrm{p}<0.05)$.

Table 3: Distribution of meatal stenosis by groups within three months

\begin{tabular}{lccl}
\hline Meatal stenosis & Group A & Group B & p value* \\
\hline Present & $00(0.0)$ & $6(10.0)$ & \multirow{2}{*}{0.036} \\
Absent & $60(100.0)$ & $54(90.0)$ & \\
Total & $\mathbf{6 0 ( 1 0 0 . 0 )}$ & $\mathbf{6 0}(\mathbf{1 0 0 . 0})$ & \\
\hline
\end{tabular}

* Yates' chi-square test has been done due to one of the value is below 5 .

** Parenthesis indicates percentage.

\section{Discussion}

Approximately one in three men is circumcised globally, but there are relatively few data on the safety of the procedure ${ }^{1}$. Male circumcision is a common surgical procedure, but few epidemiological have reported frequency of adverse events, most commonly bleeding, infection and as a late complication meatal stenosis. This is likely due to several factors directly associated with complications such as age at circumcision, training and expertise of the provider, the sterility of the conditions under which the procedure is undertaken and the indication (medical/cultural) for circumcision.

In general, complications (reported by parents) occur least frequently among neonates and infants than older boys, with majority of prospective studies in neonates and infants finding no serious complications, and relatively few other adverse events, which is minor and treatable ${ }^{16}$. Diagnosis of meatal stenosis has been reported in $0.9 \%$ to $11.0 \%$ of the boys undergoing circumcision ${ }^{17,18,19}$. However, higher rates may be seen in areas in which the procedure is done by non qualified regional people ${ }^{18}$. This present study showed that using petroleum jelly after circumcision was effective for reducing frequency of post circumcision meatal stenosis. In this study meatal stenosis was not observed in any children whose meatus and circumcision site was lubricated according to schedule for three months, while with the operation of the same surgeon, $10.0 \%$ children in control group developed meatal stenosis.

Post circumcision bleeding was observed in very less frequent cases in boys performing lubrication of the meatus and circumcision site when compared with the control group. Bleeding has been reported as the most common early complication after circumcision and its prevalence was $3.3 \%$ to $10.0 \%$, depending on the experience and talent of the practitioner and the technique used ${ }^{19}$. The main goal of this study was to prevent meatal stenosis, but lubrication was also effective in reducing early episode of bleeding. This is a good results regarding infection in the meatus and circumcision site. Different statistical findings, ranging from $0.1 \%$ to $3.3 \%$, have been reported in other studies for the prevalence of infection at the circumcision site ${ }^{20}$. These are usually depend on the practitioner skill and technique used. There were no similar studies to show the effect of lubrication on this kind of infection. Okeke* reported application of bland petroleum jelly to the external urethral meatus in boys with chemical urethritis and yielding promising results. Lubrication might be effective in reducing inflammation of the procedure site, and consequently, in reducing rate of infection.

\section{Conclusion}

Based on findings it can be concluded that using petroleum jelly (Vaseline) on meatus and circumcision site after circumcision is effective for prevention of post circumcision meatal stenosis and other complications. However more studies are needed to prove the effectiveness of lubricants for reducing post circumcision meatal stenosis and other complications.

Acknowledgement: I would like to sincerely thank to all my colleagues and others medical stuff, who helps me during this study period.

\section{References}

1. Wallerstein E. Circumcision: The Uniquely American Medical Enigma, Urologic Clinics at North America, 1985: 12; 123-132

2. Al-Ghazo MA, Banihani KE. Circumcision Revision in Male Children, Int Braz J Urol, 2006:32;454-458

3. Allen JS, Summers JL, Wilkerson JE. Meatal caliberation of newborn boys. J Urol , 1972:107;498

4. Hutson J M. Circumcision: a surgeon's perspective, J Med Ethics, 2004:30; 238-240

5. Miller GP. Circumcision: A Cultural-Legal Analysis, Virginia Journal of Social Policy and the Law, 2002: 9; 497-585

6. Angel CA, Cantu SJr. Circumcision. Available from: www.emedicine.com, Updated: Jan 25, 2010 [Access 12/03/2010]

7. Williams N, Kapila S. Complications of circumcision, British Journal of Surgery, 2005: 80; 1231-1236

8. Belman AB, Filmer BB, Immergut MA, Schoenberg HW. Urethral Meatal Stenosis in Males. Pediatrics, 1987: 61; 778-780

9. Bazmamoun H, Ghorbanpour M, Mousavi-Bahar SH. Lubrication of Circumcision Site for Prevention of Meatal Stenosis in Children Younger Than 2 Years Old, Urol J, 2008 ; 5 ;233-236 
10. Kim D, Pang M. The Effect of Male Circumcision on Sexuality, BJU International, 2007: 99; 619-622

11. Metcalf TJ, Osborn LM, Mariani EM. Circumcision: A Study of Current Practices, Clinical Pediatrics, 1983:22;575-579

12. Weiss HA, Larke N, Halperin D, Inon-Schenker I. Complications of circumcision in male neonates, infants and children: a systematic review, BMC Urology, 2010: 10

13. Griffiths DM, Atwell JD, Freeman NV. A prospective survey of the indications and morbidity of circumcision in children, Eur Urol, $1985: 11$; 184-187

14. van-Howe RS. Incidence of Meatal Stenosis following Neonatal Circumcision in a Primary Care Setting, Clinical Pediatrics, 2006:45;49-54 15. Milos MF, Macris D. Circumcision: A Medical or a Human Rights Issue?, Journal of Nurse-Midwifery, 1992:37;875-965

16. Santucci RA and Terlecki RP. Available from: www.emedicine.com Specialties Urology Common Problems of the Penis. Phimosis, Adult
Circumcision, and Buried Penis. Last Updated: Apr 15, 2009[Access 12/03/2010]

17. Ozdemir E. Significantly increased complication risks with mass circumcisions, Br J Urol,1997:80;136-139

18. Berry Jr CD, Cross Jr RR. Urethral meatal caliber in circumcised and uncircumcised males. Archives of Pediatrics \& Adolescent Medicine 1956;92(2):152.

19. Persad R, Sharma S, McTavish J, Imber C, Mouriquand PDE. Clinical presentation and pathophysiology of meatal stenosis following circumcision. British Journal of Urology 1995;75(1):91-93

20. Spach DH, Stapleton AE, Stamm WE. Lack of circumcision increases the risk of urinary tract infection in young men. JAMA:1992;267(5):679-681

21. Okeke LI, Asinobi AA, Ikuerowo OS, Epidemiology of complications of male circumcision in Ibadan, Nigeria, BMC Urol, 2006:6-8 